\title{
Comparison between Caudal Dexmedetomidine and Morphine for Postoperative Analgesia in Pediatric Infraumbilical Surgeries
}

\author{
Hamza Aboalm Mahmoud, Ahmed Elsaeed Abd Elrahman Ali, \\ Mohamed Kamal Mahmoud*, Khaled Abdelfattah Mohamed Abdelfattah \\ Department of Anesthesia, Intensive Care and Pain Management, \\ Faculty of Medicine, Sohag University, Egypt
}

*Corresponding Author: Mohamed Kamal Mahmoud, Mobile: (+20) 01016753206, Email: mohkamalhegazy@gmail.com

\begin{abstract}
Background: The usage of caudal opioids extends the length of analgesia substantially, but it often comes with a slew of adverse side effects, including fatigue, vomiting, pruritus, urinary retention, and a chance of respiratory distress later on.

Objective: The aim of this analysis was to compare the effects of caudal dexmedetomidine versus morphine in conjunction with bupivacaine in pediatric infraumbilical surgeries.

Patients and Methods: This randomized controlled sample involved 90 pediatric patients aged 1 to 7 years old, of American Society of Anesthesiologists (ASA) physical status I-II, of both sexes, who were scheduled for lower abdominal surgeries. Patients were allocated to three equal groups. Group D got a $0.25 \%$ bupivacaine $+1 \mathrm{~g} / \mathrm{kg}$ dexmedetomidine. Group $\mathrm{M}$ obtained a $0.25 \%$ bupivacaine $+30 \mathrm{~g} / \mathrm{kg}$ morphine mixture. Group MD: dexmedetomidine $1 \mathrm{~g} / \mathrm{kg}$ and morphine $30 \mathrm{~g} / \mathrm{kg}$ with bupivacaine were used in a single dose caudal epidural analgesia.

Results: Intraoperative heart rate, mean arterial blood pressure at 20, 25, 30 and 45 min was significantly decreased in group MD than group $\mathrm{D}$ and group $\mathrm{M}$ while in postoperative period were insignificantly among the three groups at all times of measurement. FLACC was significantly lower in MD group at discharge, 1, 2, 3, 6, 12 and 18 hours. Ramsey sedation score (RSS) at 30 min was significantly decreased in group M than group D and in group MD than group $\mathrm{M}$. Time for $1^{\text {st }}$ analgesia and paracetamol dosage was significantly earlier in group $\mathrm{M}$ than group $\mathrm{D}$ and group MD. Pruritus and vomiting were significantly lower in group D than other groups.

Conclusions: The addition of dexmedetomidine to caudal morphine in pediatric patients produced longer postoperative analgesia, more sedation and with better emergence from anesthesia and hemodynamic stability, with fewer side effects than morphine.
\end{abstract}

Keywords: Caudal, Dexmedetomidine, Morphine, Pediatrics.

\section{INTRODUCTION}

One of the most widely employed regional anesthetic approaches of pediatric surgery is the caudal epidural block ${ }^{(1)}$. The biggest drawback with caudal anesthesia is that it only lasts a brief time following a single injection of local anesthetic solution, which is partly attributable to infection fears. As a result, supplementary drugs have been used to induce elongation of caudal analgesia using a "one shot" process (epinephrine, opioids, ketamine, midazolam, tramadol, neostigmine, dexmedetomidine) (2). Adding morphine as a second agent aids in ensuring successful and long-lasting analgesia whilst still allowing a lower dosage of local anesthetic to be used, increasing protection and lowering the risk of undesirable motor blockade ${ }^{(3)}$.

However, there are a variety of side effects, such as nausea and vomiting, urinary leakage, pruritus, and hypoventilation, the most dangerous of which is respiratory distress in adults and infants ${ }^{(4)}$.

The aim of this research is to compare the intraoperative hemodynamics, postoperative analgesia, and complications of caudal morphine and dexmedetomidine alone or in combination for pediatric patients undergoing infraumbilical surgeries.

\section{PATIENTS AND METHODS:}

This randomized controlled prospective analysis was performed at Sohag University Hospital from June 2019 to June 2020.

\section{Ethical approval:}

An approval of the study was obtained from Sohag University academic and ethical committee. The parents of all patients who were candidates for clinical testing were asked to sign a consent form.

The research involved 90 pediatric patients aged 1 to 7 years old of American Society of Anesthesiologists (ASA) physical status I and II of both sexes who were scheduled for lower abdominal surgeries, such as hernia, and perineal surgeries, such as undescended testis and hypospadias.

Patient's family rejection, overweight participants, coagulation problems, preexisting neurological or spinal conditions, congenital malformations of the spine, allergy to any medication included in the research, inflammation and skin lesions at the puncture site were all exclusion requirements. 
Preoperative investigations involved a full blood count, coagulation profile, renal function checks, blood grouping, and proper examination of the airway for all patients.

The patients were randomized into three equal classes using the closed envelop system in a double blinded (patients (parents) and outcome assessor) manner. Group D ( $n=30)$ : Bupivacaine 0.25 percent + dexmedetomidine $1 \mathrm{~g} / \mathrm{kg}$ were given to the patients. Patients in Group M $(n=30)$ obtained a 0.25 percent bupivacaine $+30 \mathrm{~g} / \mathrm{kg}$ morphine combination. Group MD $\quad(n=30)$ obtained a single dose of dexmedetomidine $1 \mathrm{~g} / \mathrm{kg}$ and morphine $30 \mathrm{~g} / \mathrm{kg}$ with bupivacaine for caudal epidural analgesia.

All patients were given $0.01 \mathrm{mg} / \mathrm{kg}$ atropine I.M. 30 minutes before being transferred to the operating room. Normal monitors such as pulse oximetry, electrocardiogram, capnography, and noninvasive blood pressure were utilized while the patient was in the operating room. After inducing inhalational general anesthesia with $8 \%$ sevoflurane in $100 \%$ oxygen, patients were put in a supine position and a 24 G IV line was installed. Patients were intubated with $0.5 \mathrm{mg} / \mathrm{kg}$ atracurium and anesthesia was sustained with $1 \%$ sevoflurane in $50 \%$ nitrous oxide in oxygen with regulated mechanical ventilation (tidal volume $8-10 \mathrm{ml} / \mathrm{kg}$, respiratory rate (R.R) $16-20 \mathrm{c}$ $/ \mathrm{min}$ regular $\mathrm{ETCO}_{2}$ ). Atropine $0.02 \mathrm{mg} / \mathrm{kg}$ and neostigmine $0.05 \mathrm{mg} / \mathrm{kg}$ IV were used to reverse muscle relaxants by the end of the surgery.

\section{Technique of caudal anesthesia:}

The caudal anesthesia was performed anatomically in the sacral portion of the epidural space using 22-gauge $3 \mathrm{~cm}$, sterile and disposable needle. Patient's position was lateral (fetal) where the legs, knees, neck are flexed. Under complete aseptic condition, entry point of the needle was identified by an anesthesiologist's finger of the non-dominant hand as a triangular depression between the 2 sacral cornua above the coccyx below. According to Armitage formula $2.5 \mathrm{mg} / \mathrm{kg}$ without adrenaline or $1 \mathrm{mg} / \mathrm{kg}$ for thoracolumbar block. If more than $1 \mathrm{ml} / \mathrm{kg}$ to (a maximum dose of $20 \mathrm{ml}$ ) needs to be given it is preferable to avoid caudal route and go for a higher epidural route for lesser volume of drug.

In all patients, heart rate, mean arterial blood pressure (MAP), respiratory rate (R.R) and oxygen saturation at baseline, after induction, with skin incision and every 5 minutes intraoperative till the end of surgery and postoperatively at $30 \mathrm{~min}, 1,2,3,6,9$, 12, 18 and $24 \mathrm{hr}$, the FLACC score at $30 \mathrm{~min}, 1,2,3$, $6,9,12,18$ and $24 \mathrm{hr}$, rescue antiemetic and complications as disturbed conscious level, nausea, vomiting and prolonged motor block were recorded.

\section{Statistical analysis}

SPSS v25 (SPSS Inc., Chicago, IL, USA) was used to analyze the results. The mean, standard deviation (SD) and range of quantitative variables were described and compared using one-way ANOVA test. The frequency and percent of qualitative data were provided and compared using the Chi-square or Fisher's exact test. $\mathrm{P}$ values of less than 0.05 were deemed significant.

\section{RESULTS}

The three groups had no statistically meaningful differences in patient characteristics (age, sex, surgical length, and onset of caudal block) (Table 1).

Table (1): Patients' characteristics among the three groups

\begin{tabular}{|c|c|c|c|c|c|}
\hline & & $\begin{array}{c}\text { Group D } \\
(\mathbf{n}=\mathbf{3 0})\end{array}$ & $\begin{array}{c}\text { Group M } \\
(\mathbf{n}=\mathbf{3 0})\end{array}$ & $\begin{array}{c}\text { Group MD } \\
(\mathbf{n}=\mathbf{3 0})\end{array}$ & $P$ value \\
\hline \multirow{2}{*}{$\begin{array}{l}\text { Age } \\
\text { (years) }\end{array}$} & Mean \pm SD & $2.97 \pm 1.35$ & $2.95 \pm 1.40$ & $3.13 \pm 1.57$ & \multirow{2}{*}{0.897} \\
\hline & Range & $1-5.5$ & $1-6$ & $0.58-6$ & \\
\hline \multirow[t]{2}{*}{ Sex } & Male & $23(109.52 \%)$ & $23(109.52 \%)$ & $25(119.05 \%)$ & \multirow{2}{*}{0.766} \\
\hline & Female & $7(33.33 \%)$ & $7(33.33 \%)$ & $5(23.81 \%)$ & \\
\hline \multirow{2}{*}{$\begin{array}{l}\text { Duration of } \\
\text { surgery (min) }\end{array}$} & Mean \pm SD & $46.5 \pm 13.27$ & $41.33 \pm 9.37$ & $45.5 \pm 12.75$ & \multirow{2}{*}{0.086} \\
\hline & Range & $30-60$ & $30-60$ & $30-60$ & \\
\hline \multirow{2}{*}{$\begin{array}{l}\text { Onset of caudal } \\
\text { block (min) }\end{array}$} & Mean \pm SD & $7.50 \pm 1.94$ & $8.07 \pm 1.98$ & $7.30 \pm 2.15$ & \multirow{2}{*}{0.320} \\
\hline & Range & $5-11$ & $5-12$ & $5-12$ & \\
\hline
\end{tabular}

Intraoperative heart rate was significantly different among the three groups at $20,25,30$ and $45 \mathrm{~min}(\mathrm{P}<0.001)$ and was insignificantly different among the three groups at baseline, induction, skin incision, 5, 10, 15 and $60 \mathrm{~min}$. Intraoperative heart rate at 20,25, 30 and 45 min was significantly decreased in group MD than group D and group MD than group $\mathrm{M}(\mathrm{P} 2<0.001, \mathrm{P} 3<0.001,<0.001,<0.001$ and 0.049 respectively) (Figure 1$)$. 


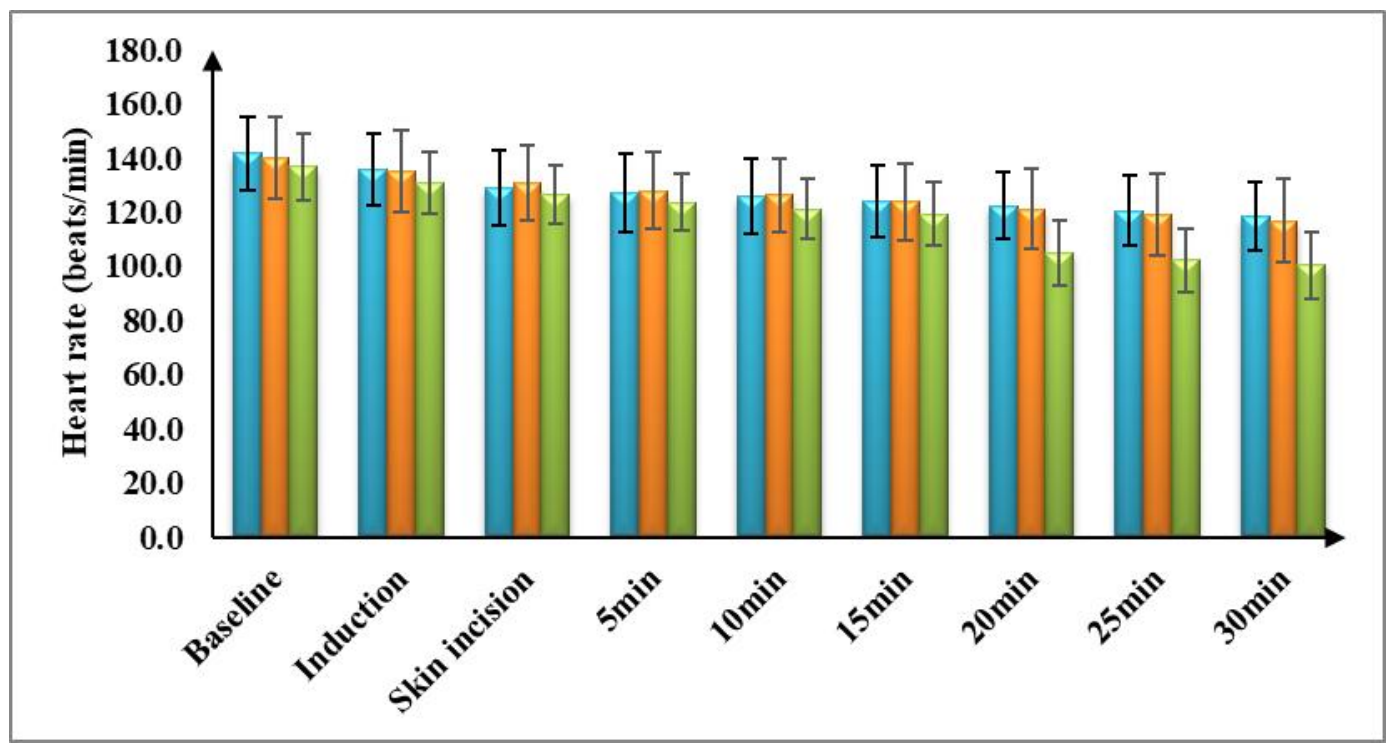

Figure (1): Intraoperative heart rate (beats/min) of the three groups

Intraoperative mean arterial blood pressure was significantly different among the three groups at 20, 25, 30 and $45 \min (\mathrm{P}=0.003,0.001,<0.001$ and 0.002 respectively $)$ and was insignificantly different among the three groups at baseline, induction, skin incision, 5, 10, 15 and $60 \mathrm{~min}$. Intraoperative mean arterial blood pressure at 20, 25, 30 and 45 min was significantly decreased in group MD than group D and group MD than group M (P2 0.035, 0.037, 0.031 and 0.022 respectively. P3 $0.002,0.001,<0.001$, and $<0.001$ respectively) (Figure ().

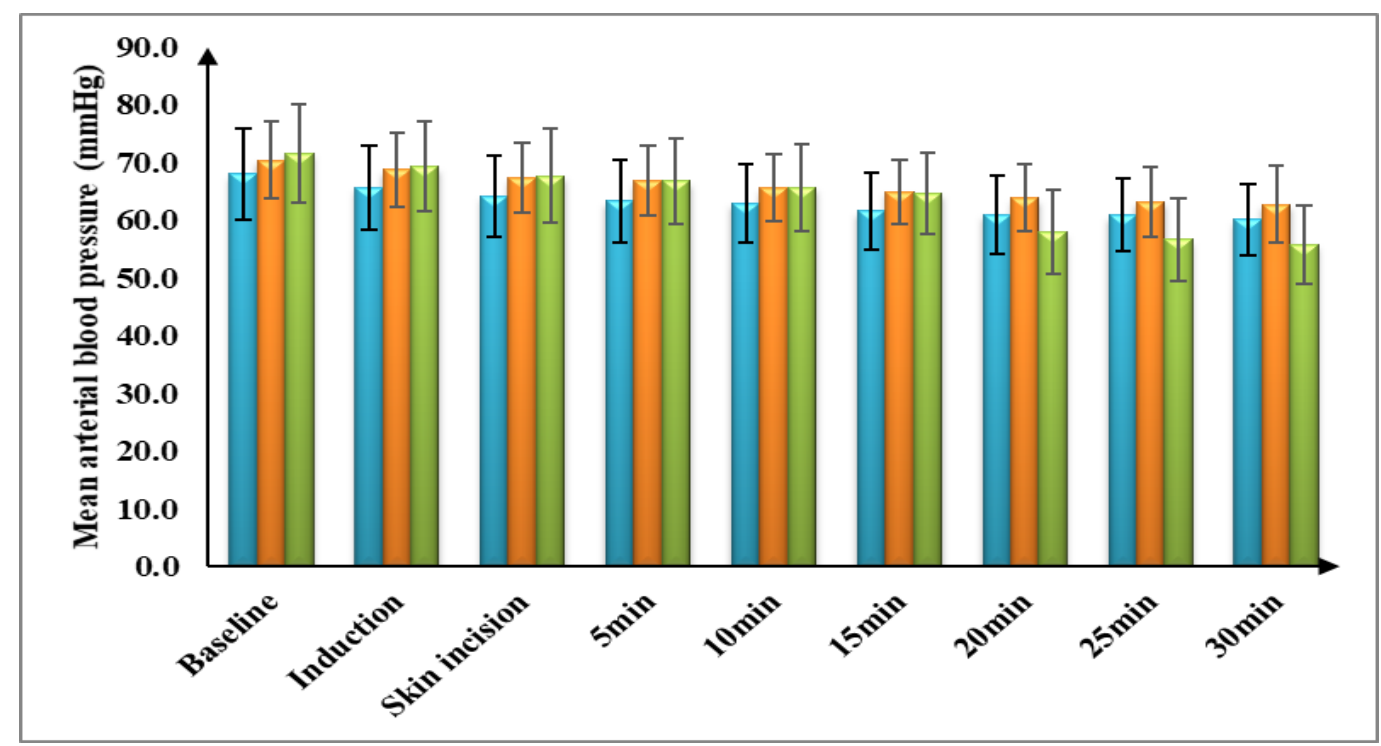

Figure (2): Intraoperative mean arterial blood pressure $(\mathrm{mmHg})$ of the three groups.

FLACC was slightly inconsistent between the three groups at discharge, 1, 2, 3, 6, 12, and 18 hours (P 0.001), but was insignificantly different at $0.5,9$, and 24 hours. FLACC was slightly lower in group MD than group D ( $\mathrm{P} 2=$ $0.009)$ and group MD than group M (P3 0.001) after 1 hour. FLACC was significantly higher in group M than in group D at 2 and 6 (P1 0.001), and significantly lower in MD than in group D (P3 0.001). FLACC was significantly higher in group $\mathrm{M}$ than in group $\mathrm{D}(\mathrm{P} 10.001)$, but significantly lower in group $\mathrm{MD}$ than in group $\mathrm{D}(\mathrm{P} 2=0.022)$ and in group MD than in group M (P3 0.001). At 12 hours, FLACC was slightly smaller in groups $\mathrm{M}$ and MD than in group D (P1 0.001, P3 0.001 respectively). At 18 hours, FLACC was slightly lower in group M than in group D (P1 $0.001)$, but significantly higher in group $\mathrm{MD}$ than in groups $\mathrm{D}$ and $\mathrm{M}(\mathrm{P} 2=0.017, \mathrm{P} 30.001$ respectively) (Figure (). 


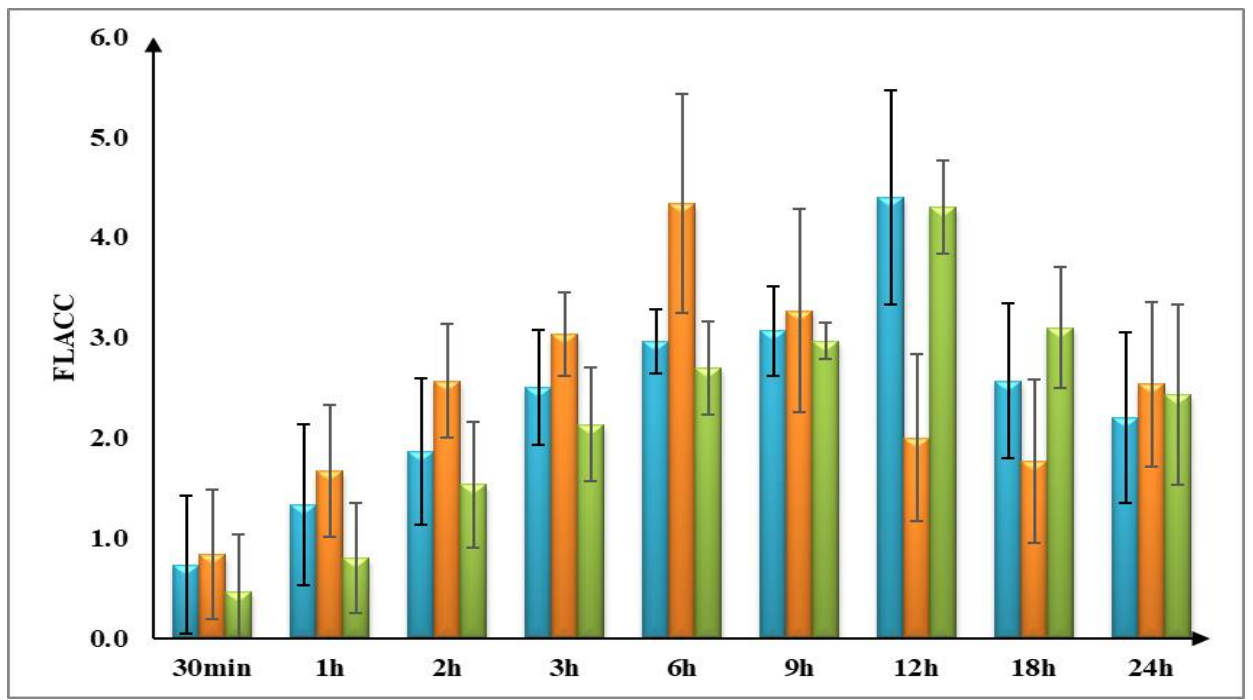

Figure (3): FLACC among the three groups.

Ramsey sedation score was significantly different among the three groups at $0.5,1$ and 2 hours $(\mathrm{P}=<0.001$, $<0.001$ and 0.009 respectively) and was insignificantly different among the three groups at 3, 6, 9, 12, 18 and 24 hours. Ramsey sedation score at $30 \mathrm{~min}$ was significantly decreased in group M than group D and in group MD than group M ( $\mathrm{P} 1<0.001, \mathrm{P} 3<0.001$ respectively). Ramsey sedation score at 1 hour was significantly decreased in group $\mathrm{M}$ and group MD than group $\mathrm{D}(\mathrm{P} 1<0.001, \mathrm{P} 2=0.007$ respectively). Ramsey sedation score at 2 hours was significantly decreased in group $\mathrm{M}$ than group $\mathrm{D}(\mathrm{P} 1=0.007)$ (Figure () .

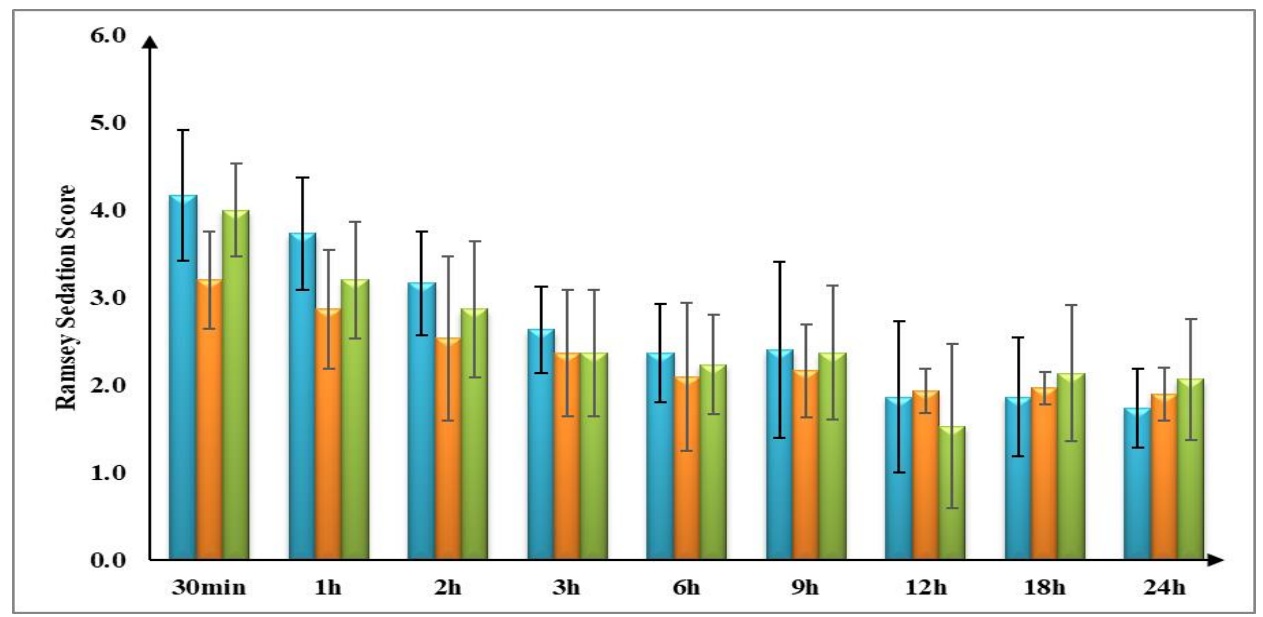

Figure (4): Ramsey sedation score among the three groups.

Time for $1^{\text {st }}$ analgesia and paracetamol dosage was significantly different among the three groups. Time for 1 st analgesia was significantly earlier in group $M$ than group D and group MD. Paracetamol dosage was significantly higher in group $\mathrm{M}$ than group $\mathrm{D}$ and group $\mathrm{MD}$ with an insignificant difference between group $\mathrm{D}$ than group $\mathrm{M}$ (Error! Reference source not found.2).

Table (2): Time for $1^{\text {st }}$ analgesia (min) and paracetamol dosage (mg/d) among the three groups

\begin{tabular}{|c|c|c|c|c|c|c|c|}
\hline & & $\begin{array}{c}\text { Group D } \\
(\mathbf{n}=\mathbf{3 0})\end{array}$ & $\begin{array}{c}\text { Group M } \\
(\mathbf{n}=\mathbf{3 0})\end{array}$ & $\begin{array}{c}\text { Group MD } \\
(\mathbf{n}=\mathbf{3 0})\end{array}$ & & valu & \\
\hline \multirow{3}{*}{$\begin{array}{c}\text { Time for } \\
1^{\text {st }} \text { analgesia } \\
(\text { min })\end{array}$} & Mean \pm SD & $457.9 \pm 54.55$ & $294.8 \pm 43.66$ & $476.45 \pm 41.79$ & \multirow{3}{*}{$0.001 *$} & $\mathrm{P} 1$ & $<0.001 *$ \\
\hline & \multirow{2}{*}{ Range } & \multirow{2}{*}{$385-550$} & \multirow{2}{*}{$223-360$} & \multirow{2}{*}{$410-540$} & & $\mathrm{P} 2$ & 0.430 \\
\hline & & & & & & P3 & $<0.001 *$ \\
\hline \multirow{2}{*}{$\begin{array}{l}\text { Paracetamol } \\
\text { dosage }(\mathrm{mg} / \mathrm{d})\end{array}$} & Mean \pm SD & $168.25 \pm 45.66$ & $228.75 \pm 57.76$ & $164.25 \pm 54.73$ & \multirow[b]{2}{*}{$<0.001 *$} & $\mathrm{P} 1$ & $0.002^{*}$ \\
\hline & Range & $80-285$ & $135-300$ & $75-270$ & & \begin{tabular}{|l|}
$\mathrm{P} 2$ \\
$\mathrm{P} 2$
\end{tabular} & 0.969 \\
\hline
\end{tabular}

*Significant

$\mathrm{P} 1$ : $\mathrm{P}$ value between group $\mathrm{D}$ and group $\mathrm{M}$

$\mathrm{P} 2$ : $\mathrm{P}$ value between group D and group DM

P3: P value between group $\mathrm{M}$ and group DM 
Pruritus, vomiting and urine retention were significantly lower in group D than other groups (Table 3).

Table (3): Side effects among the three groups

\begin{tabular}{||c|c|c|c|c|c||}
\hline \hline \multicolumn{2}{||c|}{} & $\begin{array}{c}\text { Group D } \\
(\mathbf{n = 3 0})\end{array}$ & $\begin{array}{c}\text { Group M } \\
(\mathbf{n = 3 0})\end{array}$ & $\begin{array}{c}\text { Group MD } \\
(\mathbf{n = 3 0})\end{array}$ & \multirow{2}{*}{ P value } \\
\hline \multirow{3}{*}{ Side effects } & Pruritus & $0(0 \%)$ & $12(40 \%)$ & $8(26.67 \%)$ & $<\mathbf{0 . 0 0 1}^{*}$ \\
\cline { 2 - 7 } & Vomiting & $2(6.67 \%)$ & $10(33.33 \%)$ & $9(30 \%)$ & $\mathbf{0 . 0 2 9}^{*}$ \\
\cline { 2 - 7 } & Urine retention & 0 & $8(26.67 \%)$ & $10(33.33 \%)$ & $\mathbf{0 . 0 0 3}^{*}$ \\
\hline
\end{tabular}

*Significant

\section{DISCUSSION}

Dexmedetomidine has an eight-fold higher affinity for 2 adrenergic receptors and a weaker affinity for 1 receptors than clonidine, in addition to providing a better selectivity for $2 \mathrm{~A}$ adrenergic receptors, which are responsible for the analgesic activity of both medications ${ }^{(5)}$. Jensen was the first to identify the usage of epidural morphine in 1981, and many studies since then have demonstrated that it provides profound analgesia with a range of side effects, including nausea and vomiting, urinary leakage, pruritus, and hypoventilation, the most severe of which is respiratory distress in adults and adolescents ${ }^{(4)}$.

Our findings were backed up by a study by Xiang et al. (9), who noticed that mixing caudal bupivacaine with dexmedetomidine $(1 \mathrm{~g} / \mathrm{kg})$ decreased the hemodynamic reaction to hernial sac traction in children undergoing inguinal hernia repair. Furthermore, Nasr and Abdelhamid ${ }^{(7)}$ measured the effectiveness of caudal dexmedetomidine to caudal fentanyl on the stress response and postoperative analgesia and found that the dexmedetomidine community had slightly lower HR. In comparison to the present research, they used a lower dosage of dexmedetomidine and a shorter acting drug, fentanyl, in their study (7). Furthermore, Mukhtar et al. (8) demonstrated that dexmedetomidine caused significant bradycardia and hypotension that lasted from the moment the medication was administered to the time the skin incision was produced. Our findings indicate that, in addition to offering sustained postoperative analgesia, dexmedetomidine has a desirable safety profile and healthy hemodynamics, which are compatible with the findings of many other scientists ${ }^{\text {(9- }}$ 11)

In current study, FLACC was significantly different among the three groups at discharge, 1, 2, 3, 6, 12 and 18 hours and was insignificantly different among the three groups at 0.5, 9 and 24 hours. From our results, we found that combination between, morphine and dexmedetomidine provided prolonged analgesia for $12 \mathrm{hrs}$, which was significantly prolonged than either dexmedetomidine or morphine alone. When compared between morphine and dexmedetomidine, we found dexmedetomidine provided analgesia for $6 \mathrm{hrs}$ and this significantly was prolonged than morphine.

Alpha2 adrenergic receptor agonists may extend the time of operation of bupivacaine and increase the level of analgesia by inducing local vasoconstriction and growing potassium conductance in $\mathrm{A}$ and $\mathrm{C}$ fibers, according to our explanation. They can also potentiate the action of local anesthetics by accessing the central nervous system through systemic absorption or diffusion into the cerebrospinal fluid, where they bind to 2 receptors in the superficial laminae of the spinal cord and brainstem, or indirectly stimulating spinal cholinergic neurons ${ }^{(12)}$.

In the case of morphine, binding with the opioid receptor at the dorsal horn of the spinal cord resulted in potent and long-lasting analgesic impact ${ }^{(\mathbf{1 3})}$. As a consequence, the combination of these medications creates a synergistic analgesic impact in principle. The current findings showed that adding dexmedetomidine to the analgesic impact of caudal morphine and bupivacaine improved the analgesic effect.

Nasr and Abdelhamid ${ }^{(7)}$ tested the impact of caudal dexmedetomidine versus fentanyl with bupivacaine on the stress response and postoperative analgesia in pediatric cardiac surgery, and found that dexmedetomidine attenuated the stress response and provided improved analgesia. Hetta and collaborators ${ }^{(14)}$ have looked at the effects of general anesthesia and caudal analgesia on 40 juvenile patients who were scheduled for large abdominal cancer surgery. Group I obtained $1 \mathrm{ml} / \mathrm{kg}$ of 0.25 percent bupivacaine with $1 \mathrm{mg} / \mathrm{kg}$ of dexmedetomidine, and group II received $1 \mathrm{ml} / \mathrm{kg}$ of 0.25 percent bupivacaine. They discovered that in pediatric major abdominal cancer procedures, introducing dexmedetomidine to caudal bupivacaine resulted in substantial postoperative pain reduction lasting up to 19 hours ${ }^{(14)}$. Similarly, according to Yoshitomi et al. ${ }^{(15)}$, dexmedetomidine prolongs analgesic duration in neuroaxial blocks with minimum controllable side effects as opposed to narcotic additives.

Furthermore unlike the results of the current study, Vetter $\boldsymbol{e t}$ al. ${ }^{(16)}$ compared single dose injection of morphine, clonidine combined with ropivacaine caudally in pediatric surgery, and concluded that caudal morphine produced a better quality and sustained analgesia with no difference in the pain scores among the patients. During the postoperative course, epidural clonidine $(150 \mathrm{mg})$ did not appear to be more effective than morphine ( $4 \mathrm{mg}$ ) in a research by Lund et $\boldsymbol{a l} .{ }^{(17)}$ in adults. In comparison to our findings, stronger pain 
reduction was only observed in the first 2 hours of assessment, and the morphine dosage was disproportionately large as opposed to the equivalent clonidine dose in that sample.

The Ramsey sedation score at 30 minutes was slightly lower in group $\mathrm{M}$ than group $\mathrm{D}$ and in group MD than group $\mathrm{M}$ in the present analysis. At 1 hour, the difference between groups $\mathrm{M}$ and $\mathrm{MD}$ was slightly smaller than the difference between groups D and was slightly lower in group $\mathrm{M}$ than in group D at 2 hours. Dexmedetomidine's sedative and supraspinal analgesic actions are both regulated through noradrenergic neuron hyperpolarization. This results in decreased locus ceruleus neuronal firing and norepinephrine release suppression in the descending medullospinal noradrenergic pathway ${ }^{(18)}$.

Dexmedetomidine often improves the effectiveness of local anesthetics thus lowering the risk of side effects. In contrast to other sedatives, dexmedetomidine has limited respiratory side effects in adults and infants, rendering it an outstanding adjuvant. Also at elevated levels, dexmedetomidine causes sedation that can be quickly overcome with mild stimulation and does not induce respiratory distress ${ }^{(\mathbf{1 9}}$ 20)

Our results were supported by Hetta et al. ${ }^{(14)}$ who studied the effect of general anesthesia combined with caudal analgesia on 40 pediatric patients, scheduled for major abdominal cancer surgeries divided into group I who received bupivacaine with dexmedetomidine and group II bupivacaine. They found that addition of dexmedetomidine to caudal bupivacaine in pediatric major abdominal cancer surgeries achieved significantly prolonged duration of arousable sedation (14). In another study, Anand and colleagues $^{(21)}$ studied the effect of adding dexmedetomidine to caudally injected ropivacaine on the intensity of postoperative analgesia and its safety in the children undergoing abdominal surgeries. They reported that dexmedetomidine achieved better quality of sleep and minimal agitation during recovery from anesthesia. They also reported a prolonged postoperative sedation. The addition of dexmedetomidine to bupivacaine in caudal block in children was examined by Constant et al. ${ }^{(22)}$, who observed that the dexmedetomidine group had a higher standard of sleep and a longer period of sedation. This is consistent with El-Feky and Abd El Aziz's ${ }^{(23)}$ research, which showed that using dexmedetomidine as an adjuvant to bupivacaine resulted in a longer period of arousable sedation and a lower occurrence of side effects.

As regards the total duration of postoperative analgesia as indicated by FLACC score, which gets equal or more than 4, El Shamaa and Ibrahim ${ }^{(24)}$, study included total of 50 pediatric patients 1-5 years old scheduled for lower abdominal and perineal surgeries were enrolled into group A they found patients of Group B showed a shorter sedation time (3.2 $\pm 0.6)$ compared with that of Group A $(6.2 \pm 0.5)$ which was statistically significantly different $P<0.001$. Singh et al. ${ }^{(25)}$ completed a prospective, randomized, doubleblind controlled trial of adolescents receiving upper abdominal surgery. For caudal analgesia, patients were split into two groups and given either morphine (MB) or clonidine (CB) in bupivacaine. As opposed to the MB group (3.8 \pm 0.7$) \mathrm{h} ; \mathrm{P}<0.01)$, subjects who got clonidine $(\mathrm{CB})$ were sedated for longer $(7.1 \pm 0.8) \mathrm{h}$ ). Our findings are consistent with those of Anand $\boldsymbol{e t}$ al. (21), who used dexmedetomidine as an adjuvant with 0.25 percent ropivacaine caudally and found that the time of analgesia was slightly longer in the ropivacainedexmedetomidine combination group than in the ropivacaine alone group. El-Hennawy et al. (26) compared the usage with single dose caudal epidural injections of dexmedetomidine, clonidine, or placebo (normal saline) applied to bupivacaine, and observed that the length of analgesia was considerably increased with dexmedetomidine, and to a lesser degree with clonidine, than with pure bupivacaine. Furthermore, Xiang et al. ${ }^{(6)}$ hypothesized in an analysis of the effect of caudal dexmedetomidine that supplementing caudal bupivacaine with dexmedetomidine prolongs the time of postoperative analgesia.

In a report by Singh et al. ${ }^{(25)}$, the mean time of analgesia in children undergoing upper abdominal surgery was $16.5 \pm 3.6 \mathrm{~h}$ in the $\mathrm{CB}$ community compared to $10.2 \pm 2.3 \mathrm{~h}(\mathrm{P}<0.01)$ in the $\mathrm{MB}$ group. When opposed to the MB group, the participants who obtained clonidine (CB) were sedated for longer. Singh et al. ${ }^{(25)}$, on the other hand, contrasted the usage of caudal clonidine versus morphine with bupivacaine in pediatric patients undergoing upper abdominal surgery, and found that morphine had a longer period of analgesia and sedation than the current research. Vetter et al. ${ }^{(16)}$ also found that caudal morphine provided more prolonged initial analgesia than caudal clonidine $(\mathrm{P}=0.02)$; no differences were found in overall morphine usage, period to first oral use, or total morphine use. According to their observations, a total of 50 pediatric patients aged 1 to 5 years old who were scheduled for lower abdominal and perineal surgeries were split into two groups: group A received dexmedetomidine with bupivacaine, and group B received morphine with bupivacaine. In the PACU, side effects such as vomiting, itching, and respiratory distress were observed while morphine was used instead of dexmedetomidine ${ }^{(24)}$. Furthermore, Demiraran et al. ${ }^{(27)}$ found that the rate of side effects such as respiratory disturbance, swelling, skin rash, and vomiting was higher with morphine in their research on the usage of single dose epidural morphine for postoperative analgesia in pediatric surgery. In comparison, patients were randomly assigned to obtain a single caudal clonidine, hydromorphone, or morphine, paired with ropivacaine, in a report by Vetter $\boldsymbol{e t}$ al. ${ }^{(16)}$. 
Compared to caudal hydromorphone or caudal morphine, caudal clonidine caused fewer postoperative nausea and vomiting $(\mathrm{P}=0.01)$ and pruritus $(\mathrm{P}=$ 0.007). There was no indication of postoperative respiratory depression, prolonged sedation, hypotension, or bradycardia.

\section{CONCLUSIONS}

The addition of dexmedetomidine to caudal morphine provided longer postoperative analgesia, more sedation, and stronger emergence from anesthesia and hemodynamic control in pediatrics, with fewer side effects than morphine.

\section{Financial support and sponsorship: Nil Conflict of interest: Nil.}

\section{REFERENCES}

1. Kendigelen P, Tutuncu A, Emre $S$ et al. (2016): Pudendal versus caudal block in children undergoing hypospadias surgery: A randomized controlled trial. Reg Anesth Pain Med., 41:610-5.

2. Cook B, Doyle E (1996): The use of additives to local anaesthetic solutions for caudal epidural blockade. Paediatr Anaesth., 6:353-9.

3. Sailo S, Zodinpuia M, Naveen $\mathbf{P}$ (2020): Study of morphine with ropivacaine and ropivacaine alone for caudal epidural analgesia in children. Int J Surg., 7:781-6.

4. Semsroth M, Gabriel A, Sauberer A et al. (1994): Regional anesthetic procedures in pediatric anesthesia). Anaesthesist, 43:55-72.

5. Asano T, Dohi S, Ohta S et al. (2000): Antinociception by epidural and systemic alpha (2)-adrenoceptor agonists and their binding affinity in rat spinal cord and brain. Anesth Analg., 90:400-7.

6. Xiang Q, Huang D, Zhao Y et al. (2013): Caudal dexmedetomidine combined with bupivacaine inhibit the response to hernial sac traction in children undergoing inguinal hernia repair. Br J Anaesth., 110:420-4.

7. Nasr D, Abdelhamid H (2013): The efficacy of caudal dexmedetomidine on stress response and postoperative pain in pediatric cardiac surgery. Ann Card Anaesth., 16:109-14.

8. Mukhtar A, Obayah E, Hassona A (2006): The use of dexmedetomidine in pediatric cardiac surgery. Anesth Analg., 103:52-6.

9. Ramsay M, Luterman D (2004): Dexmedetomidine as a total intravenous anesthetic agent. Anaesthesiology, 101:787-90.

10. Berkenbosch J, Wankum P, Tobias J (2005): Prospective evaluation of dexmedetomidine for noninvasive procedural sedation in children. Pediatr Crit Care Med., 6:435-9.

11. Nichols D, Berkenbosch J, Tobias J (2005): Rescue sedation with dexmedetomidine for diagnostic imaging: a preliminary report. Paediatr Anaesth., 15:199-203.

12. Gertler R, Brown H, Mitchell D et al. (2001): Dexmedetomidine: a novel sedative-analgesic agent. Proc (Bayl Univ Med Cent), 14:13-21.
13. Bujedo B (2014): Spinal opioid bioavailability in postoperative pain. Pain Pract., 14:350-64.

14. Hetta D, Fares $K$, Abedalmohsen A et al. (2018): Epidural dexmedetomidine infusion for perioperative analgesia in patients undergoing abdominal cancer surgery: randomized trial. J Pain Res., 11:2675-85.

15. Yoshitomi T, Kohjitani A, Maeda $S$ et al. (2008): Dexmedetomidine enhances the local anesthetic action of lidocaine via an alpha-2A adrenoceptor. Anesth Analg., 107:96-101.

16. Vetter T, Carvallo D, Johnson J et al. (2007): A comparison of single-dose caudal clonidine, morphine, or hydromorphone combined with ropivacaine in pediatric patients undergoing ureteral reimplantation. Anesth Analg., 104:1356-63.

17. Lund C, Qvitzau S, Greulich A et al. (1989): Comparison of the effects of extradural clonidine with those of morphine on postoperative pain, stress responses, cardiopulmonary function and motor and sensory block. Br J Anaesth., 63:516-9.

18. Carollo D, Nossaman B, Ramadhyani U (2008): Dexmedetomidine: a review of clinical applications. Curr Opin Anaesthesiol., 21:457-61.

19. Ishii H, Kohno T, Yamakura T et al. (2008): Action of dexmedetomidine on the substantia gelatinosa neurons of the rat spinal cord. Eur J Neurosci., 27:3182-90.

20. Afonso J, Reis F (2012): Dexmedetomidine: current role in anesthesia and intensive care. Rev Bras Anestesiol., 62:118-33.

21. Anand V, Kannan M, Thavamani A et al. (2011): Effects of dexmedetomidine added to caudal ropivacaine in paediatric lower abdominal surgeries. Indian $\mathbf{J}$ Anaesth., 55:340-6.

22. Constant I, Gall O, Gouyet L et al. (1998): Addition of clonidine or fentanyl to local anaesthetics prolongs the duration of surgical analgesia after single shot caudal block in children. Br J Anaesth., 80:294-8.

23. El-Feky E, Abd El Aziz A (2015): Fentanyl, dexmedetomidine, dexamethasone as adjuvant to local anesthetics in caudal analgesia in pediatrics: A comparative study. Egyptian Journal of Anaesthesia, $31: 175-80$.

24. El Shamaa H, Ibrahim M (2014): A comparative study of the effect of caudal dexmedetomidine versus morphine added to bupivacaine in pediatric infra-umbilical surgery. Saudi Journal of Anaesthesia, 8:155-162.

25. Singh R, Kumar N, Singh $P$ (2011): Randomized controlled trial comparing morphine or clonidine with bupivacaine for caudal analgesia in children undergoing upper abdominal surgery. Br J Anaesth., 106:96-100.

26. El-Hennawy A, Abd-Elwahab A, Abd-Elmaksoud A et al. (2009): Addition of clonidine or dexmedetomidine to bupivacaine prolongs caudal analgesia in children. $\mathrm{Br} \mathrm{J}$ Anaesth., 103:268-74.

27. Demiraran Y, Kocaman B, Akman R (2005): A comparison of the postoperative analgesic efficacy of single-dose epidural tramadol versus morphine in children. $\mathrm{Br} \quad \mathrm{J}$ Anaesth., 95:510-3. 